\title{
Role of folic acid deficiency as a possible risk factor for erectile dysfunction
}

\author{
Attia Abdallah Attia, Mohamed Abdelmawgoud Amer, Nagah Mohamed A.Mohamed, Ahmed \\ Mahmoud Mohamed Alhabashi \\ Department of Dermatology and Venerology Department, Faculty of Medicine, Al Azhar University \\ Corresponding author: Ahmed Mahmoud Mohamed Alhabashi, Mobile: 00201023296171, E-Mail: \\ ahmed.alhabashi1985@gmail.com
}

\begin{abstract}
:
Background: erectile dysfunction (ED) is the persistent inability to attain or maintain an erection. ED affects millions of men worldwide. The pathophysiology of ED includes vasculogenic, neurogenic, hormonal, anatomical, drug-induced and psychogenic causes. Endothelial dysfunction (EDys) is an important pathophysiologic factor underlying vasculogenic erectile dysfunction. The pathogenesis of both EDys and ED are linked through decreased expression and activation of endothelial nitric oxide synthase (NOS) which is responsible for formation of Nitric Oxide (NO). NO is a relaxing factor which plays a major role in activation and maintenance of the erection process.

Aim of the work: this study aimed to detect the possible relationship between serum folic acid and erectile dysfunction by measuring serum FA concentration in patients with erectile dysfunction and comparing them with the healthy controls. Methodology: our study has been carried out on 90 individuals who were categorized into two groups. Group 1:60 married males complained of ED. Group 2: 30 married potent males as a control.All participants were subjected to : personal history, past history of medical diseases and operations, sexual history, general examination, genital examination and evaluation of erectile function according to the International Index of Erectile Function (IIEF-5) Questionnaire). Fasting serum samples were collected from all participants and assayed for serum total testosterone, serum prolactin, serum cholesterol, serum triglycerides (TG), HbA1c and serum folic acid.Results: results of the current study showed a significant relation between folic acid and ED. FA level was declined as ED severity increased. It is thought that ED severity was related to HHcy which was related to the severity of FA deficiency. Conclusion: a significant association between serum FA level and ED severity was detected in the current study. Serum FA level decreased as the severity of ED increased. These results suggest that FA deficiency might reflect the severity of ED.

Recommendations: serum folic acid assessment as a part of the routine investigations for patients complaining with erectile dysfunction. Additional experimental and clinical studies are needed to determine whether FA supplementation may be beneficial for patients having ED.
\end{abstract}

Keywords: folic acid, erectile dysfunction

\section{Introduction}

Erectile dysfunction (ED) is defined as the persistent inability to attain or maintain an erection sufficient to permit satisfactory sexual performance ${ }^{(1)}$.Erectile dysfunction is the major component of male sexual dysfunction which negatively affects the quality of life for millions of men worldwide (2).The pathophysiology of ED included vasculogenic, neurogenic, hormonal, anatomical, druginduced and psychogenic causes ${ }^{(3)}$.Penile erection is a vascular event that requires an intact endothelium and vascular smooth muscles of the corpus cavernosum. The pathogenesis of both endothelial dysfunction and ED are linked through decreased expression and activation of endothelial nitric oxide synthase (NOS) which is responsible for formation of Nitric Oxide (NO). Nitric oxide (NO) is a relaxing factor which plays a major role in activation and maintenance of the erection process ${ }^{(4)}$.Homocysteine is a potent NOS inhibitor as it promotes NOS uncoupling reducing the production of the endothelial (NO). Hyperhomocysteinemia was recently reported to be a novel ED risk factor ${ }^{(5)}$.Folic acid play an important role in metabolism of NO and homocysteine as it promotes the remethylation of homocysteine (Hcy) to methionin (Met) and inverts NOS uncoupling. FA deficiency prevents remethylation of homocysteine and permits its accumulation, which induces endothelial dysfunction (EDys) ${ }^{(6)}$. According to Hamidi et al. ${ }^{(7)}$, FA supplementation improved ED. They found FA supplementation therapy to be clinically useful, and the IIEF scores were three times higher in the diabetic patients with ED taking tadalafil and FA in combination than in those taking 
tadalafil monotherapy in a 3-month therapy setting. In addition, a study showed that FA supplementation improved endothelial dysfunction in patients with DM or hypertension ${ }^{(8)}$.Their findings suggested that FA was closely related to the erection mechanism and FA supplementation might be used in the treatment of ED. Therefore, in this study we tried to evaluate serum FA levels in patients with ED and compared them to those of healthy controls.

\section{Aim of the Work}

The aim of this work was to study the possible relationship between serum folic acid and erectile dysfunction by measuring serum FA concentration in patients with erectile dysfunction and comparing them with the healthy controls.

\section{Subjects and Methods}

This study had been carried out on 90 individuals who were categorized into two groups:

- Group 1: 60 married males complaining of ED.

- Group 2: 30 married potent males as a control.

\section{Inclusion criteria:}

- Men complaining of ED for 6 months at least.

- Married men only.

- Age: above 30 years old.

\section{Exclusion criteria:}

Patients with other risk factors for ED were excluded.

- Significant cardiac diseases (severe decompensated heart failure, unstable angina and myocardial infarction).

- Neurological diseases (ex. MS, Parkinsonism, cerebral stroke, CNS tumors, spinal cord injury, spinal cord diseases and CNS operations).

- Major psychiatric disorders (ex. depression and anxiety).

- Thyroid diseases.

- Renal insufficiency.

- Hepatic insufficiency.

- Pelvic trauma and pelvic operations (ex.prostatectomy and urethral operations).

- Penile trauma (ex. penile fracture) and penile operations.

- Dyslipidemia (cholesterol > $200 \mathrm{mg} / \mathrm{dl}$ and/or TG > $150 \mathrm{mg} / \mathrm{dl}$ ).
- Hormonal disturbances affecting the sexual functions:

1- Hypogonadism (serum total testosterone (TT) $<2 \mathrm{ng} / \mathrm{ml}$ )

2- Hyperprolactinemia (serum prolactin level $>20 \mathrm{ng} / \mathrm{ml}$ )

- Using drugs that affect sexual function or sexual desire.

1- Antidepressants (ex. Selective serotonin reuptake inhibitors (SSRI) \& Tricyclic antidepressants).

2- Sedatives (ex. Benzodiazepines).

3- Anti-psychotic drugs.

4- Anti-hypertensive medications (especially Diuretics \& Beta blockers).

5- Anti-epileptic drugs (ex.Tegretol).

6- Substance abuse (ex. Opioids, Marijuana, Cocaine).

All participants were subjected to the following:

\section{Personal History}

Name, age, residence, occupation, marital status, smoking, alcohol intake and drug abuse

\section{Past History:}

- History of medical diseases that may be risk factors for $\mathrm{ED}$, particularly diabetes mellitus, hypertension, coronary heart disease, liver or kidney and neurological disorders.

- History of pelvic trauma or pelvic surgery.

- History of drug intake especially those affecting sexual function

- History of operations, accidents or genital trauma.

3. Sexual history:

The following items are evaluated according to the sexual activities during the previous 6 months:

- Onset, course and duration of the condition.

- Presence of morning erections, their frequency and quality.

- Any erectile episodes occuring with visual or manual stimulation or extramarital relations.

- Frequency of intercourse and last Sexual coitus 
- Presence of libido and whether orgasm and ejaculation are achieved during coital attempts.

- Relation of the couple and the partner's attitude toward sex and if there is any marital troubles.

- Presence of factors that may precipitate psychogenic erectile dysfunction as anxiety, depression, phobia or history of any psychic disorders.

\section{Physical examination:}

- General examination:

- Genital examination:

- Penoscrotal examination: the penis was inspected for the size and site of the urethral meatus and is palpated for tenderness or plaques. Any penile deviation was noted. Patients with penile deviation, Peyronie's disease or penile fibrosis were excluded from the study.

- Genital examination included measurement of testicular size, consistency (whether the testes are rubbery, firm, hard, or soft).

5. Evaluation of erectile function according to the International Index of Erectile Function (IIEF-5) Questionnaire:

The International Index of Erectile Function - 5 Questionnaire (IIEF-5) is a convenient, reliable, validated and widely used as a diagnostic tool for erectile dysfunction. It is a self-administered questionnaires and have been demonstrated to have a high degree of sensitivity and specificity to ED ${ }^{(3)}$.

Classification of ED was partitioned into five severity grades: no ED total score (22$25)$, mild (17-21), mild to moderate (12-16), moderate (8-11) and severe ED (1-7). Patients with a score of 21 or less may have evidence of $\mathrm{ED}^{\left({ }^{(9)} \text {. }\right.}$

All patients answered the Arabic version of IIEF-5 questionnaire in structured interview. It is a validated Arabic version of the IIEF-5 ${ }^{(10)}$.

\section{Investigations:}

All individuals were studied between 8 and 10 am after a 12-hour overnight fast. Venous blood was sampled for measurement of:

1- Serum total testosterone (TT).

2- Serum prolactin.

3- Serum cholesterol.
4- Serum triglycerides (TG).

5- HbA1c.

6- Serum folic acid.

Subjects with hypogonadism (serum total testosterone $<2 \mathrm{ng} / \mathrm{ml}$ ), hyperprolactinemia (serum prolactin level $>20$ $\mathrm{ng} / \mathrm{ml}$ ), dyslipidemia (cholesterol $>200 \mathrm{mg} / \mathrm{dl}$ and/or TG $>150 \mathrm{mg} / \mathrm{dl}$ ) were excluded from the study as previously menthioned in the exclusion criteria.

Fasting serum folic acid levels were measured using Enzyme-linked Immunosorbent Assay (ELISA) kit for folic acid (CEA610Ge, USCN Life Science Inc. Wuhan-China).

Assay procedure of serum FA measurement ncluded:

Reference range of serum folic acid measured $5-15 \mathrm{ng} / \mathrm{mL}$.

The procedure of measurement was done according to the kit protocol as follows: leaving samples and reagents at room temperature for 30 minutes. Then, $50 \mu \mathrm{L}$ of standard or samples were added to corresponding well followed by addition of $50 \mu \mathrm{L}$ prepared detection reagent $\mathrm{A}$ with shaking and mixing and incubation for 1 hour at $36^{\circ} \mathrm{C}$. Aspiration and washing were done for 5 cycles in Biotek Washer Instrument, USA sn: 233397 by using $350 \mu \mathrm{L}$ wash. $100 \mu \mathrm{L}$ of prepared detection reagent $\mathrm{B}$ were added and incubated for 30 minutes at $36^{\circ} \mathrm{C}$ followed by aspiration and washing for 5 cycles. $90 \mu \mathrm{L}$ of substrate solution were added and incubated for 15 minutes at $30^{\circ} \mathrm{C}$ followed by addition of 50 $\mu \mathrm{L}$ of stop solution. Reading was done at a wave length $450 \mathrm{~nm}$ on Biotek reader, USA sn: 233754.

\section{Statistical methods:}

\section{Statistical analysis:}

Data were analyzed using Statistical Program for Social Science (SPSS) version 18.0. Quantitative data were expressed as mean \pm standard deviation (SD). Qualitative data were expressed as frequency and percentage.

Where, $\Sigma$ : Sum, (Xi): each value in the series and $\mathbf{n}$ : number of values in the series.

\section{The following tests were done:}

- Independent-samples t-test of significance was used when comparing between two means.

- Pearson's correlation coefficient (r) test was used for correlating data.

- Receiver operating characteristic (ROC curve) 
- Analysis was used to find out the over all predictivity of parameter in and to find out the best cut-off value with detection of sensitivity and specificity at this cut-off value.

- Sensitivity: Probability that a test result will be positive when the disease is present (true positive rate, expressed as a percentage).

- Specificity: Probability that a test result will be negative when the disease is not present (true negative rate, expressed as percentage).

\section{RESULTS}

Table 1: comparison between patients and control as regard age (years), height, Weight and Body mass Index (BMI)

\begin{tabular}{|c|c|c|c|c|c|c|}
\hline & Control group & Patients group & \multirow{2}{*}{ Test value• } & \multirow{2}{*}{ P-value } & \multirow{2}{*}{ Sig. } \\
\hline & & No. $=30$ & No. $=60$ & & & \\
\hline Age & $\begin{array}{c}\text { Mean } \pm \text { SD } \\
\text { Range }\end{array}$ & $\begin{array}{c}34.13 \pm 6.36 \\
23-47\end{array}$ & $\begin{array}{c}54.00 \pm 9.73 \\
31-70\end{array}$ & -10.134 & $<0.001$ & $\mathrm{~S}$ \\
\hline Height & $\begin{array}{c}\text { Mean } \pm \text { SD } \\
\text { Range }\end{array}$ & $\begin{array}{c}174.27 \pm 6.02 \\
165-187\end{array}$ & $\begin{array}{c}173.58 \pm 4.83 \\
163-185\end{array}$ & 0.582 & 0.562 & NS \\
\hline Weight & $\begin{array}{c}\text { Mean } \pm \text { SD } \\
\text { Range }\end{array}$ & $\begin{array}{c}88.07 \pm 8.45 \\
74-105\end{array}$ & $\begin{array}{c}90.17 \pm 11.23 \\
70-124\end{array}$ & -0.903 & 0.369 & NS \\
\hline BMI & $\begin{array}{c}\text { Mean } \pm \text { SD } \\
\text { Range }\end{array}$ & $\begin{array}{c}29.06 \pm 3.58 \\
22.9-36.5\end{array}$ & $\begin{array}{c}29.92 \pm 3.59 \\
22.9-45.5\end{array}$ & -1.076 & 0.285 & NS \\
\hline
\end{tabular}

NS: Non significant; S: Significant.

$\bullet:$ Independent t-test

This table showed a statistically significant difference between patients and control as regard age (years), using independent t-test.

Table 2: comparison between patients and control as regard diabetes mellitus (DM), hypertension (HTN) and smoking:

\begin{tabular}{|c|c|c|c|c|c|c|c|c|}
\hline & & \multicolumn{2}{|c|}{ Control group } & \multicolumn{2}{|c|}{ Patients group } & \multirow{2}{*}{$\begin{array}{c}\text { Test } \\
\text { value* }\end{array}$} & \multirow{2}{*}{ P-value } & \multirow{2}{*}{ Sig. } \\
\hline & & No. & $\%$ & No. & $\%$ & & & \\
\hline DM & $\begin{array}{l}\text { Yes } \\
\text { No }\end{array}$ & $\begin{array}{c}1 \\
29\end{array}$ & $\begin{array}{c}3.3 \% \\
96.7 \%\end{array}$ & $\begin{array}{l}12 \\
48\end{array}$ & $\begin{array}{l}20.0 \% \\
80.0 \%\end{array}$ & 4.496 & 0.034 & $\mathrm{~S}$ \\
\hline HTN & $\begin{array}{l}\text { Yes } \\
\text { No }\end{array}$ & $\begin{array}{c}1 \\
29 \\
\end{array}$ & $\begin{array}{c}3.3 \% \\
96.7 \% \\
\end{array}$ & $\begin{array}{l}19 \\
41 \\
\end{array}$ & $\begin{array}{l}31.7 \% \\
68.3 \% \\
\end{array}$ & 9.289 & 0.002 & $\mathrm{~S}$ \\
\hline Smoking & $\begin{array}{l}\text { Yes } \\
\text { No }\end{array}$ & $\begin{array}{c}3 \\
27\end{array}$ & $\begin{array}{l}10.0 \% \\
90.0 \%\end{array}$ & $\begin{array}{l}21 \\
39\end{array}$ & $\begin{array}{l}35.0 \% \\
65.0 \%\end{array}$ & 6.392 & 0.011 & $\mathrm{~S}$ \\
\hline
\end{tabular}

*:Chi-square test

This table showed a statistically significant difference between patients and control as regard

DM, Hypertension and Smoking, using Chi-square test.

Table 3: comparison between patients and control as regard investigations (serum total testosterone, serum prolactin, serum cholesterol, serum triglycerides and $\mathrm{HbA} 1 \mathrm{c})$ :

\begin{tabular}{|l|l|c|c|c|c|c|}
\hline \multicolumn{2}{|c|}{} & Control group & Patients group & \multirow{2}{*}{ Test value• } & \multirow{2}{*}{ P-value } & Sig. \\
\cline { 3 - 7 } \multicolumn{2}{|c|}{} & No. $=\mathbf{3 0}$ & No. $=\mathbf{6 0}$ & & & \\
\hline T. Testosterone & Mean \pm SD & $5.83 \pm 1.07$ & $4.10 \pm 1.66$ & 4.263 & $<0.001$ & S \\
\hline S. prolactin & Mean \pm SD & $7.82 \pm 1.92$ & $8.53 \pm 1.27$ & -1.000 & 0.320 & NS \\
\hline S. Cholesterol & Mean \pm SD & $152.13 \pm 14.75$ & $146.17 \pm 11.50$ & 0.733 & 0.465 & NS \\
\hline S. TG & Mean \pm SD & $120.20 \pm 27.65$ & $107.66 \pm 26.52$ & 1.831 & 0.071 & NS \\
\hline HbA1C & Mean \pm SD & $5.32 \pm 0.33$ & $5.92 \pm 1.58$ & -2.068 & 0.042 & S \\
\hline
\end{tabular}

$\bullet:$ Independent t-test

This table showed a statistically significant difference between patients and control as regard total testosterone and $\mathrm{HbA1c}$ using Independent t-test.

Table 4: comparison between patients and control as regard serum folic acid

\begin{tabular}{|l|l|l|l|l|l|}
\hline S. Folic acid & Control group & Patients group & Test value: & P-value & Sig. \\
\hline
\end{tabular}




\begin{tabular}{|l|c|c|c|c|c|}
\hline & No. $=\mathbf{3 0}$ & No. $=\mathbf{6 0}$ & & & \\
\hline Median(IQR) & $13.36(10.88-14.24)$ & $7.10(5.42-8.75)$ & 6.360 & $<0.001$ & $\mathrm{~S}$ \\
\hline
\end{tabular}

f: Mann Whitney test

This table showed a statistically significant difference between patients and control as regard serum Folic acid using Mann Whitney test.

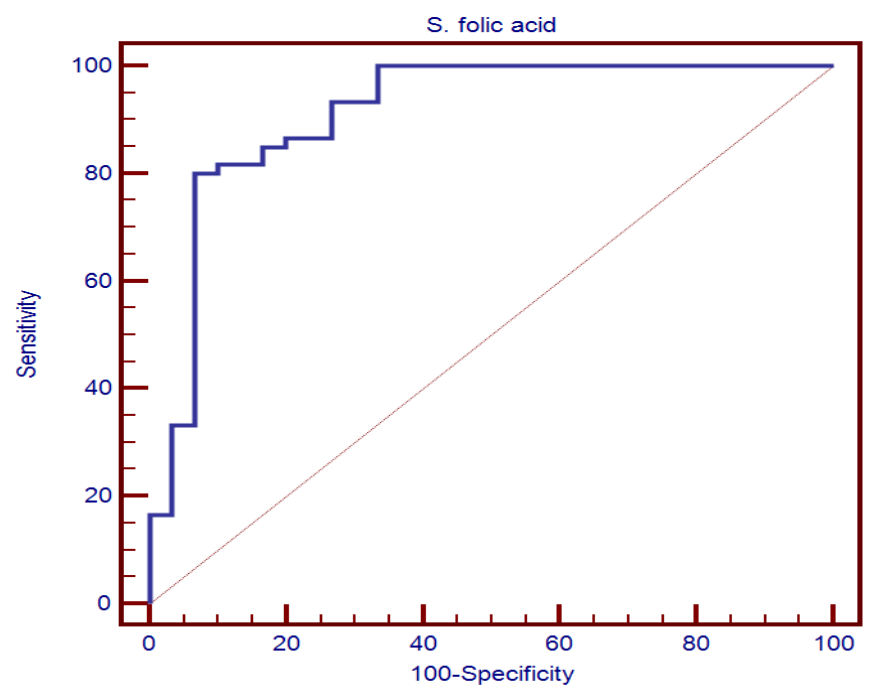

Fig. 1: ROC curve diagnostic Performance of Serum Folic Acid in Discrimination patients and control

\begin{tabular}{|l|c|c|c|c|c|c|}
\hline Parameter & AUC & Cut off Point & Sensitivity & Specificity & PPV & NPV \\
\hline S. Folic acid & 0.913 & $\leq 9.42$ & 80.00 & 93.33 & 96.0 & 70.0 \\
\hline
\end{tabular}

The previous ROC curve showed that the best cut off point to detect patients with erectile dysfunction was found $\leq 9.42$ with sensitivity of $80.00 \%$, specificity of $93.33 \%$ and area under curve (AUC) of $91.3 \%$.

Table 5: orrelation Study between (all parameters and investigations of the patients) and folic acid

\begin{tabular}{|l|c|c|}
\hline \multirow{2}{*}{} & \multicolumn{2}{|c|}{ S. Folic acid } \\
\cline { 2 - 3 } Age & $\mathbf{R}$ & p-value \\
\hline Height & $\mathbf{- 0 . 4 1 1 ^ { * * }}$ & $\mathbf{0 . 0 0 1}$ \\
\hline Weight & 0.093 & 0.479 \\
\hline BMI & -0.019 & 0.886 \\
\hline T.Testosterone & -0.105 & 0.424 \\
\hline S.prolactin & 0.202 & 0.121 \\
\hline S. Cholesterol & $\mathbf{- 0 . 2 9 8 ^ { * }}$ & $\mathbf{0 . 0 2 1}$ \\
\hline S. TG & $\mathbf{- 0 . 3 1 3 ^ { * }}$ & $\mathbf{0 . 0 1 5}$ \\
\hline HbA1C & -0.198 & 0.129 \\
\hline
\end{tabular}

This table showed a statistically significant negative correlation between age, S. prolactin, S. cholesterol and $\mathrm{HbA} 1 \mathrm{c}$ with serum folic acid, using Spearman correlation test.

Table 6: comparison between different severities of ED and control as regard serum Folic acid

\begin{tabular}{|c|c|c|c|c|c|c|c|}
\hline \multirow{2}{*}{ S. Folic acid } & Control group & Mild & Moderate & Severe & \multirow{2}{*}{ P1 } & \multirow{2}{*}{ P2 } & \multirow{2}{*}{$\mathbf{P 3}$} \\
\hline & No. $=30$ & No. $=8$ & No. $=19$ & No. $=33$ & & & \\
\hline Median(IQR) & $\begin{array}{c}13.36 \\
(10.88-14.24)\end{array}$ & $\begin{array}{c}9.91 \\
(9.48-10.84)\end{array}$ & $\begin{array}{c}7.46 \\
(6.49-7.96)\end{array}$ & $\begin{array}{c}6.18 \\
(3.78-7.48)\end{array}$ & 0.012 & $<0.001$ & $<0.001$ \\
\hline
\end{tabular}

P1: Control group Vs Mild P2: Control group Vs Moderate

P3: Control group Vs Severe

This table showed a statistically significant difference between mild, moderate and severe ED when compared with control as regard serum Folic acid using Mann Whitney test.

Table 7: comparison between patients (with and without other risk factors; DM, hypertension and smoking) and control as regard serum folic acid 
Role of folic acid deficiency as a possible risk factor for erectile dysfunction

\begin{tabular}{|c|c|c|c|c|c|c|}
\hline \multirow[t]{2}{*}{ S. folic acid } & Control group & $\begin{array}{c}\text { patients with no } \\
\text { risk } \\
\text { factors }\end{array}$ & $\begin{array}{l}\text { patients with risk } \\
\text { factors }\end{array}$ & \multirow[t]{2}{*}{ P1 } & \multirow[t]{2}{*}{$\mathbf{P 2}$} & \multirow[t]{2}{*}{ P3 } \\
\hline & No. $=30$ & No. $=33$ & No. $=27$ & & & \\
\hline Median (IQR) & $\begin{array}{c}13.36(10.88- \\
14.24)\end{array}$ & $7.69(6.23-9.89)$ & $6.72(3.78-7.48)$ & $<0.001$ & $<0.001$ & 0.013 \\
\hline
\end{tabular}

P1: Control versus patients with no risk factors P3: no risk factors versus positive risk factors

P2: Control versus patients with risk factors

This table showed a statistically significant difference between patients (both with and without other risk factors; DM, Hypertension and Smoking) and control as regard serum Folic acid and a statistically significant difference between patients with other risk factors and those with no other risk factors as regard serum folic acid using Mann Whitney test.

Table 8: multivariate logistic regression analysis for the relation between erectile dysfunction and serum folic acid after adjusting DM, HTN and smoking

\begin{tabular}{|l|c|c|c|c|c|c|c|}
\hline & \multirow{2}{*}{ B } & \multirow{2}{*}{ S.E. } & \multirow{2}{*}{ Wald } & \multirow{2}{*}{ P-value } & \multirow{2}{*}{ Odds ratio } & \multicolumn{2}{|c|}{ 95\% C.I. for OR } \\
\cline { 6 - 8 } & & & & & Lower & Upper \\
\hline DM & 2.052 & 1.567 & 1.716 & 0.190 & 7.785 & 0.361 & 167.805 \\
\hline HTN & -1.362 & 1.506 & 0.817 & 0.366 & 0.256 & 0.013 & 4.908 \\
\hline Smoking & -0.355 & 1.015 & 0.122 & 0.727 & 0.701 & 0.096 & 5.127 \\
\hline S. Folic acid & -0.738 & 0.167 & 19.607 & $<0.001$ & 0.478 & 0.345 & 0.663 \\
\hline Constant & 7.313 & 2.721 & 7.223 & 0.007 & 1499.299 & & \\
\hline
\end{tabular}

The previous table showed that there was a statistically significant association between erectile dysfunction and serum folic acid with p-value $<0.001$ after adjusting the effect of DM, HTN and smoking.

\section{Discussion}

Erection is a complex event involving the simultaneous participation of the vascular endothelium, smooth muscle bundles, autonomic nerves and extracellular matrix ${ }^{(11)}$.ED is prevalent in patients with diabetes mellitus and those with disseminated vascular diseases, such as coronary and peripheral atherosclerosis; men with penile vascular damage may also have EDys in other vascular beds ${ }^{(12)}$.ED is accepted as an early manifestation of endothelial dysfunction and cardiovascular diseases, in either the presence or absence of cardiovascular risk factors . The pathogenesis of both endothelial dysfunction and ED are linked through decreased expression and activation of endothelial nitric oxide synthase (NOS) which is responsible for formation of Nitric Oxide (NO). Nitric oxide (NO) is a relaxing factor which plays a major role in activation and maintenance of the erection process ${ }^{(13)}$.Therefore, intact endothelial function is needed for erectile function. Previous studies have also proven that FA deficiency is related to EDys ${ }^{(14)}$.Homocysteine is a potent NOS inhibitor as it promote NOS uncoupling reducing the production of the endothelial (NO)
${ }^{(15)}$.Hyperhomocysteinaemia also causes a state of oxidative stress by increasing the production of oxygen free radicals promoting oxidant injury to vascular endothelium ${ }^{(16)}$.Hyperhomocysteinemia was recently reported to be a novel ED risk factor ${ }^{(5)}$.Folic acid play an important role in metabolism of NO and homocysteine as it promotes the remethylation of homocysteine to methionin and inverts NOS uncoupling. FA deficiency prevents remethylation of homocysteine, and permits its accumulation, which induces endothelial dysfunction (EDys) ${ }^{6}$.In this study, we have evaluated the serum FA level in ED patients with different severities which were evaluated according to the IIEF-5 questionnaire. This study has been carried out on 90 individuals which were divided into two groups: group 1 (60 married males complaining of ED for at least 6 months). Group 2 (30 potent males as the control).Results of the current study showed a significant relation between serum folic acid and ED. There was a statistically significant difference between patients with mild, moderate and severe ED when compared with controls as regard serum folic acid. There was also a statistically 
significant relation between serum folic acid and severity of ED. FA level declines as ED severity increases.As regard age, there was a statistically significant relation between age and severity of ED. ED severity increases as age increases. There was also a statistically significant negative correlation between age and serum folic acid among patients with erectile dysfunction. Serum folic acid decreases as age increases.The present results also showed a statistically significant relation between smoking and serum folic acid in the patient group. Serum folic acid was lower in smokers compared to non-smokers.As regard hypertension there was also a statistically significant relation between hypertension and serum folic acid in the patient group. Serum folic acid was lower in hypertensive patients compared to normotensive patients. As regard diabetes there was a statistically significant relation between DM and serum Folic acid in the patient group. Serum folic acid was lower in diabetic patients compared to non-diabetics. Folic acid levels were lower in patients with uncontrolled DM (higher HbA1c). There was a statistically significant negative correlation between HbA1c and serum folic acid.In this study, 27 patients had other risk factors for ED (DM, Hypertension, smoking or a mixure of them) and 33 patients had non of these risk factors. There was a statistically significant difference between patients with and without other risk factors when compared with control as regard serum Folic acid. this means that folic acid deficiency can be considered an independent risk factor for ED. These results was confirmed by analysing the relation between erectile dysfunction and serum folic acid after adjusting DM, HTN and smoking which showed a statistically significant association between erectile dysfunction and serum folic acid.As regard the relation between age and ED, results of the current study are in agreement with the study of Inman et al. ${ }^{(17)}$ that was done on 1402 men to assess the association between erectile dysfunction severity and the long-term risk of coronary artery disease (CAD) and the role of age as a modifier of this association. They found that ED is more likely to develop among older men and age was the strongest predictor of ED.As regard the relation between age and serum folic acid, the results of the current study are in agreement with the study of Reynolds ${ }^{(18)}$ that showed a highest incidence of folate deficiency as measured by serum and red cell folate concentrations was in elderly populations. Chhillar et al. ${ }^{(19)}$ stated that in elderly people, folate deficiency may be related to aging; poor diet, malabsorption, drugs, or increased demand or be unexplained. Deficiency of folate is also supposed to be higher among the elderly and may increase with age due to decreased absorption caused by changes in the gastrointestinal tract.As regard the relation between hypertension and serum folic acid, the results of the current study are in agreement with the study of Scazzone et al. (20) that assessed the levels of homocysteine, vitamin B12, and folate in hypertensive patients in comparison with healthy control subjects and showed that homocysteine levels were significantly higher and folic acid levels were significantly lower in the hypertensive group in comparison to the control group. As regard the relation between DM and serum folic acid, the results of the current study were in agreement with the study of Maria and Esther ${ }^{(21)}$ which showed that patients with type 2 diabetes mellitus had increased plasma Hcy as well as decreased folic acid and vitamin B12. The exact cause why folic acid is lower in patients with type $2 \mathrm{DM}$ and if there is a link between folic acid deficiency and the pathogenesis of type 2 DM stills unclear.A trial of assessing the improvement in endothelial function by flow mediated dilatation of brachial artery after supplementation of folate at $5 \mathrm{mg}$ and vitamin B12 at $500 \mu \mathrm{g}$ in 32 obese patients with type 2 diabetes revealed a highly significant improvement in endothelial function ${ }^{(22)}$. One of the limitations of this study and we did not have enough information about relationship ED severity and Hcy level. Therefore, future studies should evaluate the relationship between ED severity and serum Hcy level. Finally, this study concluded that there was a significant association between serum FA level and ED severity. Serum FA level decreased as the severity of ED increased. These results suggested that FA deficiency might reflect the severity of ED.

\section{Conclusion}

A significant association between serum FA level and ED severity was detected in the present study. The serum FA level decreased as the severity of ED increased. Our results suggested that FA deficiency might reflect the severity of ED. 
In the future, FA supplementation may be indicated in cases with severe ED.

\section{Recommendations}

We recommended the following:

- Including serum folic acid assessment as a part of the routine investigations for patients complaining with erectile dysfunction.

- Additional experimental and clinical studies to determine whether FA supplementation may be beneficial for patients having ED and to determine the appropriate doses of FA supplemention for patients with ED and low level serum folic acid.

\section{References}

1. Hatzimouratidis $\mathrm{K}$, Giuliano $\mathrm{F}$, Moncada I et al. (2016): Guidelines on male sexual dysfunction, erectile dysfunction and premature ejaculation. Male Sexual Dysfunction, 62(3):543552.

2. Porst H (2009): Premature ejaculation. Urologe, 48: 663-674.

3. Tang $\mathrm{Z}$, Dongjie $\mathrm{L}$, Xiaobo $\mathrm{Z}$ et al. (2014): Comparison of the simplified International Index of Erectile Function (IIEF-5) in patients of erectile dysfunction with different pathophysiologies. Urology, 14:52.

4. Aversa A, Roberto B, Davide F et al. (2010): Endothelial dysfunction and erectile dysfunction in the aging man. International Journal of Urology, 17:3847.

5. Yang HF, Kao TW and Lin YY (2017):

Does serum homocysteine explain the connection between sexual frequency and cardiovascular risk?. J. Sex Med., 14:910-917.

6. Yan WJ, Yu N, Yin TL et al. (2014): A new potential risk factor in patients with erectile dysfunction and premature ejaculation: folate deficiency. Asian J. Androl., 16:902-906.

7. Hamidi $M$ A, Asadolahzade A, Mokhtari G et al. (2013): Assessment of the efficacy of combination therapy with folic acid and tadalafil for the management of erectile dysfunction in men with type 2 diabetes mellitus. J. Sex Med., 10:1146-1150.

8. Shanshan C, Wen $L$, Xin $L$ et al. (2017): Folic acid supplementation delays atherosclerotic lesion development by modulating MCP1 and VEGF DNA methylation levels in vivo and in vitro. Int. J. Mol. Sci., 18(5): 990998.

9. Cappelleri J and Rosen R (2005): The Sexual health inventory for men (SHIM) a 5-year review of research and clinical experience. International Journal of Impotence Research, 17: 307-319.

10. Shamloul $R$, Ghanem $H$ and Abouzeid A (2004): Validity of the Arabic version of the sexual health inventory for men among Egyptians. Int. J. Impot. Res., 16: 452-455.

11. Costa $C$ and Virag $R$ (2009): The endothelial-erectile dysfunction connection: an essential update. J. Sex Med., 6: 2390-404.

12. Kaiser DR, Billups $K$, Mason $C$ et al. (2004): Impaired brachial artery endothelium-dependent and independent vasodilation in men with erectile dysfunction and no other clinical cardiovascular disease. J. Am. Coll. Cardiol., 43: 179-84.

13. Gazzaruso C, Solerte SB, Pujia A et al. (2008): Erectile dysfunction as a predictor of cardiovascular events and death in diabetic patients with angiographically proven asymptomatic coronary artery disease: a potential protective role for statins and 5phosphodiesterase inhibitors. J. Am. Coll. Cardiol., 51: 2040-2048.

14. Hoch AZ, Lynch SL, Jurva JW et al. (2010): Folic acid supplementation improves vascular function in amenorrheic runners. Clin. J. Sport. Med., 20: 205-210.

15. Cheng $Z$, Xiaofeng $Y$ and Hong $W$. (2010): Hyperhomocysteinemia and Endothelial Dysfunction. Curr. Hypertens. Rev., 5(2): 158-165.

16. Hayden M R and Tyagi S C (2004): Homocysteine and reactive oxygen species in metabolic syndrome, type 2 diabetes mellitus, and atheroscleropathy: The pleiotropic effects of folate supplementation. Nutrition Journal, 3(4): 1475-2891.

17. Inman BA, Jennifer L, Debra $\mathrm{J}$ et al. (2009): A population-based, longitudinal study of erectile dysfunction and future 
coronary artery disease. Mayo. Clin. Proc., 84(2):108-113.

18. Reynolds EH. (2002): Folic acid, ageing, depression, and dementia. BMJ., 324(7352): 1512-1515.

19. Chhillar N, Neeraj K, Basu D et al. (2014): Intergenotypic variation of Vitamin B12 and Folate in AD In north indian population. Ann. Indian Acad. Neurol., 17(3): 308-312.
20. Scazzone AB, Tornese $\mathrm{F}$, Arsena $\mathrm{R}$ et al. (2014): Correlation between low folate levels and hyperhomocysteinemia, but not withvitamin B12 in hypertensive patients. Annals of Clinical \& Laboratory Science, 44(3):286-300.

21. Maria OE and Esther $O$ (2012): Elevated plasma homocysteine in type 2 diabetes mellitus: a risk factor for cardiovascular diseases. Pan African Medical Journal, 12:48.

22. Kaur U and Pandey B (2013): Role of folate in management of endothelial dysfunction. J. Clin. Prevent. Cardiol., 2(2): 91-94. 